\title{
RETRATOS DA AVÓ NA LITERATURA INFANTIL CONTEMPORÂNEA DE ANA MARIA MACHADO E RUTH ROCHA
}

Tâmara Azevedo

Elaine Pedreira Rabinovich

Resumo: A literatura, além de entretenimento, é um meio de transmitir mensagens, de reflexão e discussão das questões humanas, portanto, um importante objeto de investigação psicossocial. Visando apreender a personagem avó, analisaram-se duas histórias para crianças de duas consagradas autoras contemporâneas brasileiras, Bisa Bia Bisa Bel, de Ana Maria Machado, e Atrás da Porta, de Ruth Rocha. A metodologia qualitativa de análise de conteúdo possibilitou aventar as seguintes categorias: descrição dos personagens e de suas relações; análise dos símbolos à luz da Psicologia Analítica; contexto sócio-histórico; visão sobre educação; conceito de infância; e literatura como mensagem. As avós aparecem como representantes de geração(s) anterior(es), transmissoras da cultura e da tradição social, fontes de heranças simbólicas (cultural, familiar, intelectual), contribuindo para o desenvolvimento intelectual de seus netos e para a formação de sua identidade.

Palavras-chave: Avós. Literatura infantil. Relação intergeracional.

\section{Introdução}

A história da literatura infantil brasileira revela que o Brasil apropriou da Europa um projeto educativo e ideológico que via no texto infantil e na escola alia- 
dos imprescindíveis para a formação de cidadãos (Lajolo \& Zilbermann, 2007). Posteriormente, de traduções e adaptações de textos europeus (final do século XIX), passou-se a produzir literatura eminentemente brasileira (Peres, 2007).

À medida que houve o alargamento da infância pela escolarização crescente, a criança foi surgindo como centro de uma instituição que, ao mesmo tempo, tornou-se cada vez mais individualizada: a família. A criança passou a ter um novo papel social, motivando o aparecimento de objetos industrializados (brinquedos) e culturais (livros). Ao mesmo tempo, emergiram novos ramos da ciência (psicologia infantil, pedagogia, pediatria) a ela destinados (Lajolo \& Zilberman, 2007; Peres, 2007).

No Brasil, Monteiro Lobato é o precursor de uma concepção literária que encontrou continuidade nos anos 1970 e 1980, onde se situam as duas autoras, Ruth Rocha e Ana Maria Machado, cujas obras foram tomadas como objeto deste estudo. Essa continuidade consiste na valorização da educação mais do que da instrução; no uso da literatura de modo criativo, inovador, questionador da ordem vigente; do compromisso político decorrente de valores que passam a ser expressos em formas e conteúdos narrativos.

Os livros infantis constituem atualmente um dos segmentos mais vigorosos da indústria editorial brasileira, perdendo apenas para os didáticos. Esse sucesso editorial se deve ao interesse de adultos e crianças por ouvir e contar histórias. $\mathrm{O}$ ato de contar histórias é uma das formas mais antigas de comunicação entre os homens, seja pela oralidade, seja pela apropriação midiática (Coelho, 2003).

Por meio de histórias, a sociedade transmite conceitos, normas, que passam de geração em geração. De maneira lúdica, fácil e subliminar, a literatura atua sobre os pequenos leitores, levando-os a perceber e interrogar a si mesmos e ao mundo que os rodeia, orientando seus interesses, suas aspirações, sua necessidade de autoafirmação. Essa manifestação artística se mostra fundamental à formação e à evolução cultural do ser humano. Por esse motivo, os contos de fada deixaram de ser vistos apenas como entretenimento infantil e foram redescobertos como autênticas fontes de conhecimento do homem e do seu lugar no mundo (Coelho, 2003).

A psicanálise foi uma das linhas teóricas que mais contribuiu para o estudo dos contos de fada, em que foi interpretado o conteúdo das fantasias envolvendo, direta ou indiretamente, o imaginário familiar. Bettelheim (2007) foi o pioneiro na análise dos contos de fada. Realizou uma análise aprofundada de diversos contos de fada, mostrando suas características e como agem na mente infantil, defendendo a importância que tais contos podem ter na vida das crianças e, principalmente, na resolução de seus conflitos emocionais latentes, auxiliando-as a encontrar e formar sua identidade e seu desenvolvimento em direção à maturidade. 
Ainda sob o ponto de vista psicanalítico, Corso e Corso (2006) analisaram contos clássicos e contemporâneos, buscando relacionar os conceitos psicanalíticos às histórias contadas para crianças. Mostram que os contos de fada tratam dos temas mais íntimos às crianças: o medo, as difíceis relações familiares, a rejeição, o abandono (Branca de Neve, Cinderela, João e Maria, Pequeno Polegar, Patinho Feio, Peter Pan, Pinóquio, $O$ Grilo Falante); a função paterna reduzida, o papel da escola, a transição da infância para a adolescência (O Mágico de Oz, Harry Potter, Turma da Mônica, Peanuts, Mafalda e Calvin). Para esses autores, ouvir histórias é um dos recursos que as crianças utilizam para desenhar o mapa imaginário de seu lugar, na família e no mundo.

A psicologia analítica também contribuiu aos estudos sobre literatura infantil, sobretudo, quanto aos símbolos. O símbolo, segundo o conceito junguiano, é o termo, nome ou imagem que possui conotações além do seu significado evidente. Além dos sonhos, a psicologia analítica admite que o homem produz símbolos também nas artes em geral, incluindo a literatura (Jung, 1977). Enquanto os sonhos apresentam-se sobrecarregados de fatores de natureza pessoal, os contos de fada encenam os dramas da alma com materiais pertencentes em comum a todos os homens (Silveira, 2001; Von Franz, 2007).

Von Franz (2007) dedicou-se à interpretação dos contos de fada do ponto de vista da psicologia analítica. Para ela, a importância dos contos de fada propicia o conhecimento da psique coletiva,já que eles espelham claramente as estruturas básicas da psique. Assim, pode-se compreender como a leitura da psicologia analítica pode trazer inúmeros elementos interpretativos à compreensão da literatura infantil.

No entanto, poucos são os estudos que enfocaram a família conforme presente na literatura infantil. Em uma pesquisa, Fúlvia Rosenberg (1969) selecionou livros para meninos e para meninas, na França, concluindo que representavam uma realidade deformada e empobrecida da família, fechada em um meio de classe média. Essa conclusão estava apoiada pela inclusão de poucos grupos socioprofissionais dos pais e das mães, da ausência de famílias imigrantes, de dados demográficos como casamentos, mortes, nascimentos, e de temas tabus, donde os livros por ela selecionados não representariam uma "abertura para o mundo" que permitiria às crianças a aquisição de conhecimentos.

Pinto, Fernandes e Horta (2004) dedicaram-se à análise descritiva retrospectiva nas imagens da revista em quadrinhos da Mônica e do Cebolinha, de Mauricio de Sousa, nos períodos de 1973 a 2001. O objetivo do estudo foi identificar quais temas referentes à família eram expressos nas imagens das histórias em quadrinho. Encontrou-se o modelo de família nuclear urbana de classe média, com no máximo dois filhos e laços consanguíneos. As gerações anteriores aos pais dos personagens, a avó da Mônica e do Cebolinha, foram retratadas nos exemplares mais re- 
centes, a partir de 2000. Concluem que as imagens da família retratadas pelo autor mostraram-se capazes de unir o lúdico ao formal, podendo ser empregadas como recurso didático no processo de ensino sobre o conceito de família e termos correlacionados, como crenças, valores, mitos, transgeracionalidade, ciclo vital, especialmente infância e adolescência. Tendo como base a família retratada, afirmam que o artista, ao retratar uma família, inspira-se na sociedade em que vive e na sua vivência como membro de uma família na medida em que o artista nasce inserido em uma cultura e em uma família.

A presente pesquisa teve o objetivo de compreender a personagem avó segundo a ótica de duas autoras contemporâneas da literatura infantil nacional. Para contemplar tal objetivo, buscou-se: (1) Descrever a personagem avó nas obras Bisa, Bia, Bisa, Bel de Ana Maria Machado e Atrás da Porta de Ruth Rocha; (2) Realizar uma síntese da personagem avó a partir do olhar dessas autoras nacionais contemporâneas; (3) Comparar o tratamento das duas autoras à personagem avó; (4) Realizar uma análise geral da obra com o intuito de apontar os elementos principais que conduzem as histórias no seu objetivo de transmitir uma determinada mensagem ao leitor.

Dados demográficos apontam o crescimento do número de idosos no Brasil e no mundo. A taxa de crescimento da população brasileira com mais de 60 anos é maior do que a da população total e, atualmente, 9,1 \% da população tem mais de 60 anos, segundo o Instituto Brasileiro de Geografia e Estatística (IBGE, 2000). As avós têm sido crescentemente estudadas quanto ao seu papel na família devido à sua importância no grupo familiar, seja como apoio afetivo, educacional ou/e financeiro (Barros, 1987; Araújo \& Dias, 2002; Motta, 2004; Peixoto, 2004) e devem ser vistas dentro do quadro de diversidade social e cultural em que tal condição opera e existe.

No Brasil, na década de 1980, o estudo de Barros (1987) se tornou referência para vários estudos posteriores. Essa autora buscou demarcar a participação dessa geração na dinâmica familiar, dando destaque aos momentos pelos quais passam as famílias nas quais os avós se mostravam importantes e presentes. Mais recentemente, Dias (2002) encontrou resultados semelhantes aos de Barros (1987),enfatizando a influência que os avós exerciam na vida dos netos no que diz respeito ao aspecto emocional, sobretudo nos momentos de drama familiar em que a família se desestabiliza e precisa se reorganizar diante da nova realidade.

Outros exemplos de estudo destacam a relação intergeracional (Dias \& Pinto, 2007) e a visão dos netos sobre seus avós (Carvalho, Rabinovich, \& Moreira, 2008). O primeiro destacou o estudo dos bisavós, com o intuito de compreender a percepção desses sujeitos sobre seu papel e sua relação com os bisnetos, destacando a importância da mediação dos pais e dos netos para uma maior aproximação dos bisavós com os bisnetos. $O$ 
segundo analisou a presença de fatores de gênero e geração no discurso de crianças sobre os diversos membros da família. Concluíram que o discurso proferido pelas crianças baseava-se na experiência concreta que vivenciavam dentro da família e mostrou a existência de papéis e funções bem determinados quanto ao gênero e à geração nas famílias. Esses autores apontam que os avós parecem estar no horizonte existencial e formativo, intelectual e afetivo dessas crianças (Rabinovich \& Moreira, 2008).

Kipper e Lopes (2006) preocuparam-se com o "tornar-se avó", caracterizado como o quarto processo de individuação dentro do ciclo de vida familiar. O nascimento de um neto marca a passagem para outra fase no ciclo de vida familiar, o que muda a estrutura psíquica dos novos avós. O tornar-se avó propicia uma reflexão e uma construção particular do que é ser avó e permite que essas deem mais um passo rumo à individuação.

A anotar que a televisão assumiu, em parte, o lugar do livro para contar histórias. A maior parte das crianças e jovens só conhece os personagens e enredos de Monteiro Lobato, por exemplo, por meio das cinco adaptações televisivas e não pelas cinco mil páginas que Lobato escreveu durante vinte anos. Lobato influenciou adultos com suas narrativas e continua fazendo parte do imaginário das crianças, apesar da mudança de suporte midiático do impresso para o audiovisual (Marçolla, 2005).

Desse modo, a relevância social e acadêmica deste estudo se deve à importância crescente da literatura infantil, e devido à influência das avós no desenvolvimento de seus netos. A compreensão do papel das avós, e também dos avôs, sobre a geração seguinte, pode ser um instrumento útil para intervenções psicossociais. Como afirmam Féres-Carneiro, Ponciano e Magalhães (2007), diante de tantas novas configurações familiares, a família pode ser compreendida como um processo de passagem entre gerações. Nesse sentido, estudar como duas das mais importantes autoras em literatura infantil - e que já influenciaram várias gerações - concebem o papel de transmissão geracional, atribuindo-o à figura da avó, incide diretamente sobre o próprio conceito de família.

\section{Método}

Devido às características exploratórias do presente trabalho, a palavra "método" está sendo aqui utilizada em seu sentido etimológico: o caminho a ser percorrido, ou seja, o procedimento utilizado para alcançar o objetivo deste estudo. Desse modo, descreveremos aqui como escoIhemos e porque foram escolhidos os autores (correspondendo à descrição dos participantes e do local da pesquisa), os elementos e procedimentos da análise. 
Critério de escolha dos autores: as escolhas das duas autoras da literatura infantil brasileira contemporânea, Ruth Rocha e Ana Maria Machado, ocorreram devido à sua representatividade em território nacional, respeitando os seguintes critérios: 1 . várias gerações influenciadas por sua literatura; 2 .reconhecimento público do valor de suas obras representado por premiações e número de edições; 3 . por essas autoras abordarem o tema do nosso interesse: as avós.

Critério de escolha das obras - o"corpus empírico" do estudo: este estudo analisou apenas uma obra de cada autor.Tal decisão se deveu a vários motivos; o principal deles, o de possibilitar uma leitura aprofundada da obra em questão.

A escolha da obra de Ruth Rocha, Atrás da porta, deu-se devido ao fato de a avó ser o personagem central: mesmo depois de falecida, orienta e define o percurso da história, aproximando-a da família, da escola, da biblioteca e da cidade.

A escolha da obra de Ana Maria Machado, Bisa Bia Bisa Bel, deu-se pela existência do encontro de quatro gerações de mulheres numa mesma família, no imaginário da protagonista, e da riqueza das trocas que ocorrem entre elas.

Elementos de análise: trata-se de uma pesquisa qualitativa em que o método empregado denomina-se análise de conteúdo (Bardin, 1977), em que categorias são detectadas a partir do enunciado. Tais categorias podem tanto ser aplicadas aos textos quanto dele induzidas, sendo tais métodos denominados, respectivamente, apriorístico e empírico.

A revisão de literatura forneceu pistas preciosas, de modo que fomos buscar nos textos das duas autoras, conforme já referido, categorias apriorísticas ou dedutivas e categorias empíricas ou indutivas. As primeiras foram retiradas dos estudos elencados na revisão; as segundas foram derivadas indutivamente da leitura atenta, recorrente, indagadora e integradora das obras em pauta, quanto à temática escolhida.

Nesse sentido, foram tomados, como indicadores interpretativos apriorísticos, as seguintes categorias retiradas da literatura (Diament, 2008): 1. História da sociedade: posicionamento político e ideológico do autor, nacionalismo, internacionalismo, ditadura e valores literários; 2 . História da literatura: posicionamento do autor ante os métodos pedagógicos - literatura como instrução e educação, literatura como educação e libertação, literatura como educação (escolarização) e ascensão social e individualismo; 3 . Uso da linguagem: simplificada, coloquial, língua como tema, linearidade versus inversões de forma e conteúdo para desenvolver atitude crítica, diálogo/protagonismo; 4 . Conceito de criança e de infância: diferença entre criança e adulto, criança como autor/agente/protagonista; inocência ou não; final feliz versus conflitos (pessoais, sociais, familiares); 6. Literatura como meio de mensagem do autor. 
Quanto às categorias empíricas, na leitura de Bisa Bia Bisa Bel, de Ana Maria Machado, e Atrás da porta, de Ruth Rocha, o método consistiu em cotejar os personagens avós conforme descritos pelos autores quanto ao seu cenário, atividades, ações, relações e interações com o descrito na literatura como caracterizadores das avós no momento histórico em que tais personagens foram construídos. Uma importante categoria que emergiu da análise foi a de símbolos, quer representados graficamente, quer descritos por meio da linguagem.

Procedimentos para a análise: A análise das obras consistiu em três momentos, que serão apresentados a seguir: $1^{\circ}$ momento: descrição das personagens das obras e as relações entre elas e análise dos símbolos principais das duas obras, segundo a psicologia analítica; $2^{\circ}$ momento: análise dos conteúdos atribuídos à personagem avó na literatura infantil em pauta, contextualizados em relação ao seu momento histórico societário, literário e pessoal; $3^{\circ}$ momento: síntese das semelhanças e diferenças apontadas nas análises anteriores objetivando compreender, em principio, a relação entre: 1. autor, obra e conteúdo sócio-histórico; 2. a personagem dentro da dinâmica familiar; 3. possíveis modos de interpretação da força poética dos autores estudados conforme explicitados em seus textos.

\section{Análise das obras}

\section{Bisa Bia Bisa Bel (Ana Maria Machado)}

\section{Relações entre as personagens}

Isabel e sua mãe sempre conversavam muito. Depois do surgimento de uma foto de Bisa Bia, os diálogos aumentam e passam a se concentrar no passado, o que oportuniza mãe e filha olhar juntas para suas origens, retomando lembranças familiares e olhando para um passado que, de alguma forma, complementa o tempo presente.Ver a foto de sua mãe que já fora uma criança como ela aguça a imaginação da menina: "Eu olhava para minha mãe e para o retrato da menina, achava meio gozado aquilo, minha mãe criança, brincando no galho de um camelo pensando em balão de água" (Machado, 1990, p. 8). A visualização dessa foto antiga da mãe, assim como a foto da bisavó também criança, leva Isabel a uma viagem ao seu presente (agora menina) e futuro (adulta e idosa).

Por meio das conversas com a bisavó, Isabel tem contato com o passado, conhece coisas diferentes da sua época. Ao se encontrarem, compartilham diversos momentos da vida da menina e trocam informações sobre cultura, costumes, culinária, objetos nos diferentes tempos (o tempo dela e o da bisavó): 
Ela explica as coisas do tempo dela, eu tenho que dar explicações do nosso tempo. É que dentro do envelope, dentro da caixa, dentro da gaveta e dentro do armário, ela não tinha visto nada do que andava acontecendo por aqui esses anos todos. (p. 25)

A bisa tem uma função de amiga, de companheira, devido à imagem da Beatriz menina:"Fiquei olhando para o retrato e logo vi que não podia chamar de bisavó Beatriz aquela menina fofa com jeito de boneca" (p. 10). Bisa Bia passou a ser, para Isabel, uma amiga especial, com a qual ela dividia momentos importantes do seu dia a dia. Porém, apesar de a foto ser de uma menina, o comportamento de Bisa Bia era de bisavó, tinha uma postura adulta, de avó mesmo. Era séria, conversava, dava conselhos: "Ela me contava uma porção de coisas do tempo dela, ensinava coisas, falava de lembranças, dava conselhos - o que ela gosta de dar conselhos não dá nem para imaginar!" (p. 22).

Alguns comportamentos de Isabel incomodavam Bisa Bia:seu jeito moleca, as brincadeiras (subir em árvores, correr, brincar com meninos), pois, para ela, não eram comportamentos de uma mocinha. Devido a essas diferenças geracionais entre a bisa e a bisneta, presenciamos, ao longo da história, alguns conflitos entre essas duas personagens. Ela contestava alguns conselhos da bisavó e explicava que, no seu tempo, as coisas eram diferentes.

Neta Beta entra na história no momento em que Isabel brincava com Sérgio (garoto de quem a menina gostava) e Bisa Bia dava um de seus conselhos à neta de como deveria se comportar frente a um rapaz. Neta Beta emite sua opinião, oposta à de Bisa Bia e mais compatível naquele momento com o que pensava Isabel. Um dia, resolveu perguntar quem ela era:

Você é minha Bisa, Bisa Bel, uma gracinha de menina de short e tênis que eu encontrei nos guardados de minha mãe, numa foto velha e mandei fazer uma holografia Delta... E ela é sua Bisa Bia, a menininha que também está lá, no retrato que você segura na mão. (p. 45)

A partir do aparecimento de Neta Beta, que veio de um momento que ainda não existe (futuro), estabelece-se um diálogo entre três diferentes gerações. A relação de Isabel com Neta Beta possibilita que a garota transcenda o mundo real e presente e circule no mundo imaginário, visualize o futuro, o mundo dos seus descendentes. Promove uma ideia de continuidade, que é o curso da própria humanidade: gerações que se sucedem.

Questionadora, Isabel não concorda com Bisa Bia e, ao mesmo tempo, não concorda imediatamente com o polo oposto (Neta Beta), buscando um meio termo, a sua própria maneira de existir. E, assim, aprende a lidar com as diferenças ao entrar em contato com Bisa Bia e Neta Beta. 


\begin{abstract}
Mas também tem hora que, apesar de saber que é tão mais fácil seguir os conselhos de Bisa Bia, e que nesse caso todos vão ficar tão contentes com o meu bom comportamento de mocinha, tenho uma gana lá de dentro me empurrando para seguir Neta Beta, lutar com o mundo, mesmo sabendo que ainda vão se passar muitas décadas até alguém me entender. Mas eu já estou me entendendo um pouco - e às vezes isso me basta. (p.48)
\end{abstract}

Esse trecho representa o caminho da menina em direção à formação da própria identidade. $O$ contato com suas origens, proporcionado por Bisa Bia, e com as perspectivas de futuro, através de Neta Beta, conduzem Isabel a construir o"si mesmo", a sua própria maneira de estar no mundo. É essa atitude frente à própria existência que Simone Weil (2001) chama de enraizamento. $O$ enraizamento é uma necessidade humana ligada a vínculos com uma comunidade de origem, fonte de suas heranças simbólicas.

Símbolos, episódios-chave que conduzem à análise: lenço, leque, caixa, retrato, trança

O lenço representa a moda, os costumes da moda de determinado período na história da humanidade. Além de parte do vestuário, o lenço servia como forma de comunicação entre homens e mulheres enamorados, usado como ritual de conquista (Boléo, 2009).

Em Bisa Bia Bisa Bel, o lenço é apresentado em duas cenas importantes: a primeira, quando aparece o pai (iniciais do lenço) que diz sobre a filiação e a herança do sobrenome; a segunda, o lenço de pano como símbolo de uma época em que as mulheres não trabalhavam fora e se dedicavam somente aos afazeres da casa e à família, tendo tempo, supostamente, para se ocupar de uma atividade que tal. Além disso, Bisa Bia tenta ajudar Isabel, deixando cair o lenço, para que Sérgio pegasse e o entregasse para ela e, assim, se aproximassem para conversar (como era comum em sua época). Mas a interferência de Bisa Bia acabou dando errado, pois os comportamentos mudam a cada época e, assim, Bisa Bia esperava reações dos rapazes e de Isabel que não aconteceram. Esse acontecimento fez com que Isabel se irritasse com Bisa Bia:

Não me interessa seu tempo! Quando é que você vai entender que hoje em dia tudo é muito diferente? Eu sou eu, vivo no meu tempo, e quero fazer tudo o que tenho vontade, viver minha vida, sacou, Bisa Bia? Eu sou eu, ouviu? (Machado, 1990, p. 40)

O lenço, portanto, funciona na obra como um objeto que realiza uma passagem no tempo de vida real das personagens. 
O leque é o primeiro símbolo com o qual nos deparamos na história.É a capa do livro, em sua 8 a edição, em 1990.É um objeto antigo, muito utilizado pelas mulheres. Atualmente, é pouco utilizado. A capa do livro buscou justamente associar o objeto à geração mais antiga (as avós e bisavós) e, obviamente, ao passado. Na China, fazia parte integrante do vestuário, sendo símbolo de dignidade e poder (Vieira, 2009). No século $\mathrm{XIX}$, as damas usavam o leque para se refrescar do calor, mas, além disso, o leque servia de comunicação entre elas e os cavalheiros enquanto eles as cortejavam. Enfim, era uma fonte transmissora de mensagens entre namorados ou amantes (Vieira, 2009).

No romance Si Yeu-ki o leque se relaciona aos pássaros, como instrumento de liberação da forma, como símbolo do voo para o país dos Imortais. Por isso, quando Kiaitseu T'uei (personagem principal do romance) volta ao mundo transformado em vendedor de leques, entende-se que ele propõe uma receita de imortalidade, ou o símbolo da imortalidade que ele mesmo atingiu (Chevalier \& Gheerbrant, 1991). Essa simbologia atribuída ao leque se aplica à história de Ana Maria Machado, visto que o leque pode representar a imortalidade de Bisa Bia e das gerações a ela anteriores. Então, o leque não representa apenas um objeto antigo, usado por nossas avós, mas é a representatividade da imortalidade deles em nossas lembranças e nas heranças simbólicas deixadas para as gerações futuras.

A caixa é um objeto importante na história, pois dentro dela havia vários elementos do passado da vida de Isabel, inclusive o retrato da sua bisavó. Nela, está guardado algo de muito precioso para a família de Isabel: as lembranças. Na caixa em que estava a foto de Bisa Bia, também havia:"uma vela cor de rosa, do bolo de quando eu fiz um ano e que ela guardava de recordação, dentro de um sapatinho velho de neném, de quando eu era pequenininha" (Machado, 1990, p. 7). Havia também um envelope cheio de retratos, entre eles o de Bisa Bia. Retratos esses que reavivaram muitas lembranças à mãe de Isabel e a ela própria, tanto de histórias de sua infância como histórias de seus familiares.

A caixa é símbolo do feminino, representa o inconsciente e o corpo materno. A caixa sempre contém um segredo. Separa do mundo aquilo que é frágil, temido ou precioso (Chevalier \& Gheerbrant, 1991). Abrir uma caixa representa sempre um risco, pois seu conteúdo pode acarretar mudanças para quem a abriu e teve acesso a ele, recordando o mito da caixa de Pandora (Chevalier \& Gheerbrant, 1991). Isabel e sua mãe foram afetadas pela abertura da caixa na medida em que tiveram contato com seu conteúdo (as lembranças familiares) e essas lembranças acarretaram uma série de acontecimentos ao longo da história.

O retrato é um elemento importante na história, pois é o pontapé inicial para toda a aventura vivida por Isabel, no contato com seus antepassados (representados por Bisa Bia) e com o futuro (representado por 
Neta Beta).O retrato representa um registro, uma lembrança, um momento que a pessoa registra e guarda em uma imagem estática. $O$ costume de guardar retratos de família evoca a noção de arquivo e o interesse pela memória devido à transitoriedade e à velocidade do tempo. Silva (2008) classifica o álbum de família como um tipo de arquivo sentimental privado no qual retratamos paixões familiares. Mais do que fotografia e linguagem, o álbum pode ser visto como um arquivo do sujeito humano que luta contra o esquecimento. Ao arquivar fotos, o homem luta contra o que ele mais teme, que é a destruição da própria vida. Para esse autor, o álbum de fotografias nos torna conscientes do nosso próprio envelhecimento com o passar dos anos. "O tempo da foto é passado. Registro do que já não é... Desse modo, a foto é tempo que já existiu" (Silva, 2008, p. 99).

A fotografia serviu na história como evocação, memória, lembranças da família de Isabel e deu novo rumo à sua vida As imagens do passado trouxeram lembranças e novas emoções no presente. Assim também a foto que Isabel tira no presente vai servir de lembrança para sua bisneta Beta. Esses retratos arquivados guardam a história da família.

No final da história, aparece a trança simbolizando o entrelace das três gerações da família de Isabel: ela, a bisavó e sua neta, uma influenciando a outra. Ao mesmo tempo em que cada parte representa cada uma delas, juntas formam também "um", que é a trança. Cada parte é uma parte individual e cada uma tem sua importância, pois, sem cada uma das partes não existiria trança.

Eu, Bel, uma trança de gente igualzinho a quando faço uma trança no meu cabelo divido em três partes e vou cruzando umas com as outras, a parte de mim mesma, a parte de Bisa Bia, a parte de Neta Beta. E Neta Beta vai fazer o mesmo comigo, a Bisa Bel dela e com alguma bisneta que não dá nem para eu sonhar direito. E sempre assim. Cada vez melhor. Para cada um e para todo mundo. Trança de gente. (Machado, 1990, p. 56)

Ao se considerar uma "trança de gente", a menina se vê como uma rede de fios imbricados, todos unidos e interligados que forma essa unidade. Ela própria é uma rede de "fios", que são suas vivências e aprendizados, a influência do meio em que vive. $E$ assim ela se vê influenciando e sendo influenciada por elas e ela,"trança de gente", vai formando sua identidade e seu modo de estar no mundo e o modo como fazer seu próprio caminho. 


\section{Atrás da porta (Ruth Rocha)}

Relação entre as personagens: D. Carlotinha e Carlinhos

A obra é conduzida pelas lembranças de Carlinhos em relação à avó, inspiradora das suas aventuras. Movido pelas lembranças e pela saudade, Carlinhos revisita o quarto da avó mexendo em suas coisas, nos seus objetos antigos. O contato de Carlinhos com os objetos da avó é uma passagem importante da obra, pois representa uma proximidade com esta através das coisas que ela deixou. Bosi (2003) tratou dos objetos deixados pelos mais velhos. Esses objetos representam um elo familiar com o passado e cada objeto representa uma experiência vivida, uma aventura afetiva do seu possuidor. Os objetos, por ela denominados "objetos biográficos", são insubstituíveis, pois representam o seu possuidor. É o desejo de Carlinhos ao eternizar os objetos da avó. Ali, no quarto de D. Carlotinha, ele descobriu uma porta misteriosa que dava para uma enorme biblioteca.

Esse encontro do passado com o presente de modo atemporal retrata os conhecimentos, costumes e cultura que uma geração deixa de herança para a outra e que tem, como alicerce para essa transmissão, a família. Assim, a avó é retratada nessa obra como detentora da sabedoria e introdutora do protagonista ao mundo da leitura, do conhecimento e da imaginação. A própria biblioteca descoberta por Carlinhos representa uma herança, não em forma material, mas simbólica,cultural."Para Carlinhos, aquela era uma coisa mágica, era como se fosse um sonho, um espaço desconhecido" (Rocha, 1997, p. 10). E ainda:"Ele achava que aquela sala era um milagre que a sua avó tinha preparado para ele" (p. 14). Aos poucos, as crianças amigas vão tendo acesso à biblioteca, sempre à noite e à luz de velas, até os pais de Carlinhos descobrirem o que se passava e obrigarem a escola, à qual a biblioteca pertencia, a reabri-la para uso das crianças.

A biblioteca, a herança deixada por D. Carlotinha para a comunidade infantil, representou um avanço, pois as crianças agora tinham a liberdade de ir à biblioteca escolher o livro que quisessem ler. Esse fenômeno se afirma atualmente no Brasil, onde as grandes livrarias oferecem um "canto criança", com mesinhas e cadeiras pequenas, estantes e livros à altura das crianças, que podem assim assimilar tal espaço, concebido e dirigido a elas, de modo prazeroso.

Símbolos, episódios-chave que conduzem à análise:vela, livro, porta, casa

O livro começa e termina com a ilustração de uma vela que, além disso, acompanha todo o decorrer da história. A vela acesa é o símbolo da 
individuação (Chevalier \& Gheerbrant, 1991).“Cada um trazia sua própria vela para poder ver os livros, ler à vontade e brincar com as mil coisas interessantes que todos os dias eles iam descobrindo" (p. 15). Cada criança, segurando a sua vela, é sinal de autonomia: cada um, com sua própria luz, na busca de seus próprios conhecimentos, de suas próprias verdades.

A figura de Carlinhos com uma vela na mão, abrindo uma porta demasiadamente misteriosa, trás à luz a simbologia da vela e seu poder de oferecer luminosidade, calor, esperança, novas possibilidades e descobertas. Vê-se, portanto, ante a possibilidade de um conhecimento que é um autoconhecimento. Ao convidar os seus amigos para viver essa experiência, essa se torna um conhecimento compartilhado, isto é, uma experiência da própria cultura.

O livro não é apenas símbolo da ciência e da sabedoria, é símbolo do universo na medida em que pode conter metaforicamente todo o universo. Um livro fechado significa a matéria virgem. Um livro aberto significa que a matéria está fecundada (Chevalier \& Gheerbrant, 1991).

Podemos fazer uma analogia do livro com a biblioteca da escola Carlotinha de Araújo: fechada, escondia todo o conhecimento; aberta, oferece o conhecimento que ali se encontra para quem quiser acessá-lo. A biblioteca fechada pode simbolizar uma negação de acesso ao conhecimento. No momento em que as crianças "invadem" a biblioteca nas madrugadas, elas "exigem" o acesso ao conhecimento que lhes foi negado, o que acontece com a reabertura da biblioteca, uma reabertura para o mundo do conhecimento. O livro pode ser lido também como a metáfora da própria história: ela própria um livro dentro de outro livro, dentro de outro livro - o desenrolar da História.

A porta é símbolo catalisador da história, ao lado da vela. Está no próprio título, que se repete metaforicamente: atrás indica uma passagem e porta indica frente/trás. Pode ser lido, assim, que o centro da história é essa passagem que simboliza a divisão e a transição entre dois mundos distintos, entre o conhecido e o desconhecido, a luz e as trevas, o tesouro e a pobreza. Ela tem um valor dinâmico, psicológico, pois não somente indica uma passagem, mas convida a atravessá-la (Chevalier \& Gheerbrant, 1991). Abrir uma porta e atravessá-la é mudar de meio, mudar de vida.

A simbologia da porta nos aproxima do eixo principal da obra de Ruth Rocha, que é a busca do conhecimento, da própria autonomia e a porta enquanto passagem como transformação. Ao passar de um mundo conhecido para o desconhecido, promove a transformação daquele que o atravessa e a transformação da realidade.

Casa e escola, quando Dona Carlotinha vivia, eram uma coisa só. Pode-se dizer que essa junção simboliza uma união da escola-família, comum antes da educação formal. Com a institucionalização da escola, deu-se essa separação. 
No momento em que se passa a história, casa e escola encontramse separadas. Essa separação casa-escola pode ter o intuito de representar a separação dessas duas instituições na atualidade, limites separando instituições que deveriam trabalhar em conjunto. Outro destaque a ser dado é a co-residência, processo muito comum em famílias (Peixoto, 2004). É o que acontece na família de Carlinhos, que morava com a avó, no casarão que a ela pertencia.

Segundo o seu simbolismo, a casa significa o ser interior, é o símbolo puro do si próprio (Chevalier \& Gheerbrant, 1991). Carlinhos e sua família moravam num casarão, herança de Dona Carlotinha. Até mesmo com a doação de parte da casa para a escola, essa guarda uma identidade com a avó de Carlinhos, pois o mundo dos livros, da imaginação e do aprendizado, é o próprio mundo dessa avó. Dessa maneira, a autora representa que o conhecimento é um só, que pode advir de várias fontes e que deve ser ofertado às crianças de modo a ajudar sua integração como pessoas.

\section{Semelhanças e diferenças entre as duas obras}

Contexto sócio-histórico: o livro de Ana foi produzido na década de 80 (1982), enquanto o livro de Ruth no início da década de 90 (1991). As duas autoras vivenciaram a ditadura militar e, no momento de suas obras, viviam um período marcante para a história do século $X X$ do ponto de vista dos acontecimentos políticos e sociais: a pós-ditadura. A literatura encontra nesse período um nicho adequado ao seu crescimento, vista inclusive como meio de ascensão e protagonismo social. Nesse momento de abertura política e, consequentemente, cultural, a produção literária dessas autoras cresceu significativamente, assim como cresceu a indústria nacional de livros. O momento político abre portas para a criação dessas autoras, de modo que temas como a democratização e o papel feminino, entre outros, aparecem em suas obras.

Narrativas e ilustração: a história de Ana Maria Machado é contada em primeira pessoa, produzindo o pensamento da protagonista. Já Ruth é quem conta a história, na qual visualizamos o posicionamento do autor e a mensagem que pretende transmitir, mais do que os pensamentos e sentimentos mais íntimos do protagonista (Carlinhos). As imagens na obra de Machado caminham com o texto. No texto de Rocha, a imagem conta a história em conjunto com o texto, formulando por si um texto imagético. Nas histórias infantis, muitas vezes, ilustrações podem ser tão importantes quanto o texto.

Visões sobre educação e transmissão do conhecimento: Ruth Rocha chama atenção para o fato de que a educação deveria incorporar a literatura 
de forma prazerosa, partindo do interesse das crianças, sobre o que elas têm curiosidade, sobre o que gostariam de ler e não apenas leituras impostas, como na educação formal. De maneira geral, a educação é vista por essas autoras como uma forma de desenvolvimento e crescimento das pessoas em direção a uma educação libertária ao desenvolver nas crianças um senso crítico, ajudando-as a se posicionar no mundo enquanto sujeitos.

Conceito de criança e infância: nas duas obras, a criança é apresentada tendo interesse pela investigação, curiosidade, busca de autonomia e de conhecimento. Donas de um olhar crítico, que não aceitam coisas prontas, e que se animam quando a escola relaciona-se à sua vida. Ana Maria Machado e Ruth Rocha veem a criança como co-construtora da sua identidade e da sua formação. Sua intenção é que os pequenos leitores, por si sós, busquem suas próprias respostas.

Literatura como meio de mensagem do autor: a revisão de literatura aponta para o desejo dos escritores em deixar a sua mensagem para a sociedade e sua herança para as gerações. É no prazer em ler que as autoras se apegam para mostrar ao seu jovem leitor o caminho da liberdade e do conhecimento.

\section{Considerações finais}

Como herdeiras de Monteiro Lobato, Machado e Rocha mostram, nas obras estudadas, questões sociais vividas no país. Esses três autores se utilizaram da literatura para crianças e jovens como meio de interferir e transformar a realidade social decorrente de uma preocupação com o contexto sócio-histórico-cultural em que viviam. Outra herança lobateana deixada para suas herdeiras foi a preocupação com a boa leitura. Ambas as obras mostram uma preocupação com o hábito da leitura, discutem e criticam a educação formal, o contexto em que se dá o conhecimento, contemplando o incentivo à leitura e à educação mais prazerosas, em que o educando se sinta aguçado em sua curiosidade e busque o conhecimento não somente nos livros como fora deles.

As avós, nas duas obras, representam as gerações anteriores, os antecedentes, o encontro do passado no presente, a passagem da cultura, dos costumes. Representam o encontro das gerações atuais com a sua origem, assim contribuindo para a formação de sua identidade. As autoras propõem que os legados geracionais transmitidos pelos avós fazem parte da memória familiar e contribuem para a vida cotidiana da família. Mostram a importância de conhecer o percurso da história na medida em que esse é caminho da própria humanidade. 
De uma maneira geral, a literatura que se dedicou a pesquisar as avós e sua relação com a família concorda com as ideias transmitidas por Ana Maria Machado e Ruth Rocha de que as avós exercem influência na vida dos netos no que diz respeito ao aspecto emocional e de transmissão de conhecimento. As avós aparecem como detentoras da sabedoria e parecem estar no horizonte afetivo e intelectual dos netos.

A velhice não é o foco nas obras dessas duas autoras. Não há ideia de velhice como último estágio, limitações e proximidade da morte, apesar de o tema morte aparecer nos dois livros. Mesmo tendo morrido, as avós das histórias permanecem vivas em suas heranças, e nas lembranças, deixadas aos seus descendentes.

Grand-mother's portraits in contemporary child literature of Ana Maria Machado and Ruth Rocha

Abstract: Besides leisure, literature is a means to present messages, reflection and discussion about human issues, therefore an important subject to psychosocial investigation. Aiming to understand the grandmother as a character two stories for children written by two well known Brazilian writers were analyzed, Bisa Bia Bisa Bel, by Ana Maria Machado and Atrás da Porta (Behind the Door), by Ruth Rocha. The qualitative approach of content analysis allowed the following categories: description of the characters and of their relationships; symbol analysis using Analytical Psychology; socio-historical context; authors' comprehension about education; concept of infancy; and literature as a means for author's message. Grand-mothers were presented as representing a previous generation(s), transmitting cultural and social tradition, sources of symbolic heritage (cultural, familiar, intellectual), contributing to their grandchildren's intellectual development and identity formation.

Keywords: Grand-mother. Child literature. Intergenerational relationship.

Portraits de la grand-mère dans la littérature pour enfants de Ana Maria Machado et Ruth Rocha

Résumé: La littérature, au delà d'être un loisir, est un moyen de transmettre des messages, de réflexion et de discussion sur les questions humaines, donc un important objet d'investigation psychosociale. En ayant comme but d'identifier le personnage grand-mère, on a analysé deux histoires pour les enfants écrites par deux écrivains 
brésiliennes contemporaines, Bisa Bia Bisa Bel, de Ana Maria Machado et Atrás da Porta (Derrière la porte), de Ruth Rocha. En utilisant une méthodologie qualitative d'analyse de contenu, I'analyse des oeuvres a pris les catégories suivantes: description des personnages et de leurs relations ; analyse des symboles à partir de la Psychologie Analytique; contextes sociaux et historique; vision sur l'éducation; concept d'enfance; et littérature comme message. Les grand-mères ont été présentées comme des représentantes de génération(s) précédente(s) qui transmissent la culture et la tradition sociale, sources des héritages symboliques (culturelle, familiale, intectuelle), en contribuant au développement intellectuel de leurs petits-enfants et à la formation de leur identité. Plus que des personnages, elles émergent comme des transmetteurs de la propre humanité.

Mots-clés: Grand-mère. Littérature. Relation inter-générations.

\section{Retratos de la abuela en la literatura infantil contemporánea en Ana Maria Machado y Ruth Rocha}

Resumen: La literatura, además de entretenimiento, es un medio de presentar mensajes, reflección y discusiones de cuestiones humanas, donde es un importante objeto de investigación psicosocial. Objetivando comprender el personaje de la abuela, fueran analizados dos libros para niños de dos consagradas autoras contemporáneas brasileñas, Bisa Bia Bisa Bel, de Ana Maria Machado, y Atrás da Porta, de Ruth Rocha. La metodología cualitativa de análisis de contenido permitió las siguientes categorías: descripción de los personajes y de sus relaciones; análisis de los símbolos a la luz de la Psicología Analítica; contexto sociohistórico; visión sobre la educación; concepto de niñez; y literatura como mensaje. Las abuelas surgen como representantes de generación(es) anterior(es), transmisoras de la cultura y de la tradición social, fuentes de herencias simbólicas (cultural, familiar, intelectual), contribuyendo para el desarrollo intelectual de sus nietos y para la formación de su identidad.

Palabras clave: Abuela. Literatura infantil. Relación intergeneracional. 


\section{Referências}

Araújo, M. R. G. L., \& Dias, C. M. S. B. (2002). Papel dos avós: apoio oferecido aos netos antes e após situações de separação/divórcio dos pais. Estudos de Psicologia, 7(1), 91-101.

Bardin, L. (1977). Análise de conteúdo. Lisboa: Ed. 70.

Barros, M. L. (1987). Autoridade e afeto: avós, filhos e netos na família brasileira. Rio de Janeiro: Jorge Zahar.

Bettelheim, B. (2007). A psicanálise dos contos de fada (A.Caetano, trad., 21a ed.). São Paulo: Paz e Terra.

Boléo, M. L. V. (2009, 14 de fevereiro). Pegue na agulha e borde... um lenço de namorados. Notícias Magazine. Recuperado em 17 de junho de 2009, de www.leme.pt/destaques/lencos.

Bosi, E. (2003). O tempo vivido da memória: ensaios de Psicologia Social (2a ed.). São Paulo: Ateliê Editorial.

Carvalho, A. M. A., Rabinovich, E. P., \& Moreira, L. V. C. (2008). Gênero e geração como fatores na compreensão da criança sobre a família. In L.V.C. Moreira, G. Petrini \& F. Barbosa (Orgs.), O pai na sociedade contemporânea (pp. 181-200). Petrópolis, RJ: Vozes.

Chevalier, J., \& Gheerbrant, A. (1991). Dicionário de símbolos: mitos, sonhos, costumes, gestos, formas, figuras, cores, números (V. Costa e Silva, R. S. Barbosa, Â. Melim \& L. Melim, trads., 4a ed.). Rio de Janeiro: José Olympio.

Coelho, N.N. (2003). O conto de fadas: símbolos, mitos, arquétipos.São Paulo:DCL.

Corso, D. L., \& Corso, M. (2006). Fadas no divã: psicanálise nas historias infantis. Porto Alegre: Artmed.

Diament, N. (2008). Histoire des livres pour les enfants. Du Petit Chaeron rouge à Harry Potter. Montrouge: Bayard.

Dias, C. M. S. B. (2002). A influência dos avós na dimensão familiar e social. Symposium, 6(1/2), 34-38.

Dias, C. M. S. B., \& Pinto, V. C. (2007). A percepção dos bisavós sobre seu papel. Revista de Enfermagem UFPE, 1(2), 198-203. 
Féres-Carneiro, T., Ponciano, E. L. T., \& Magalhães, A. S. (2007). In C. M. O. Cerveny (Org.), Família em movimento (pp. 23-36). São Paulo: Casa do Psicólogo.

Instituto Brasileiro de Geografia e Estatística. (2002). Perfil dos idosos responsáveis pelos domicílios no Brasil: 2000. Rio de Janeiro: Autor.

Jung, C.G.(1977).Chegando ao inconsciente.In C.G.Jung \& M.-L.Von Franz (Orgs.), O homem e seus símbolos (M. L. Pinho, trad., pp. 18-103). Rio de Janeiro: Nova Fronteira.

Kipper, C. D. R., \& Lopes, R. S. (2006). O tornar-se avó no processo de individuação. Psicologia:Teoria e Pesquisa, 22(1), 29-34.

Lajolo, M., \& Zilbermann, R. (2007). Literatura infantil Brasileira: histórias \& histórias (7a ed.). São Paulo: Ática.

Machado, A. M. (1990). Bisa Bia Bisa Bel (8a ed.). Rio de Janeiro: Salamandra.

Marçolla, R. (2005). Os telenetos de Lobato: literatura infantil na televisão. In S. F.V. Flory (Org.), Narrativas ficcionais: da literatura às mídias audiovisuais. São Paulo: Arte e Ciência.

Motta, A. B. (2004). Sociabilidades possíveis: idosos e tempo geracional. In C. E. Peixoto (Org.), Família e envelhecimento (pp. 109-142). Rio de Janeiro: Ed. da FGV.

Peixoto, C.E. (2004). Família e envelhecimento. Rio de Janeiro: Ed. da FGV.

Peres,A.M.C.(2007). Literatura infanto-juvenil: para que fazer? Suplemento, 1306, 3-9.

Pinto, J.P., Fernandes, M.G. O., \& Horta, A. L. M. (2004). Representação da família na arte: análise da estória em quadrinhos. Psicologia em Estudo, 6(1), 21-26.

Rabinovich, E. P., \& Moreira, L. V. C. (2008). Significados de família para crianças paulistas. Psicologia em Estudo, 13(3), 437-445.

Rocha, R. (1997). Atrás da porta (18a ed.). Rio de Janeiro: Salamandra.

Rosenberg, F. (1969). La famille dans les livres pour enfants. Paris: Magnard.

Silva, A. (2008). Álbum de família: a imagem de nós mesmos (S. M. Dalinsli, trad.). São Paulo:Ed.Senac.

Silveira, N. (2001). Jung: vida e obra (18a ed.). Rio de Janeiro: Imago. 
Vieira, M.C. (2009). O leque e sua história. Recuperado em 15 de junho de 2009, www.brasilcult.pro.br/estudos/leque

Weil, S. (2001). O enraizamento (M. L. Loureiro, trad.). Bauru:EDUSC.

Von Franz, M.-L. (2007). A interpretação dos contos de fada (M.E.S. Barbosa, trad., 6a ed.). São Paulo: Paulus. 
Tâmara Azevedo, mestre pelo programa de pós-graduação em Família na Sociedade Contemporânea da Universidade Católica do Salvador. Endereço para correspondência:Rua João Mendes da Costa Filho, 263, Jardim Armação, Salvador, BA, Brasil. CEP:44 750-190.Endereço eletrônico:tamytamyaz@gmail.com

Elaine Pedreira Rabinovich, professora e pesquisadora da Universidade Católica do Salvador. Endereço para correspondência: Rua Maranhão, 101, apto. 101, São Paulo, SP, Brasil.CEP:01240-001.Endereço eletrônico: elainepr@brasmail.com.br

Recebido: 02/03/2011

Aceito:06/09/2011 